\title{
Crime and Discrimination in the Labor Market: An Empirical Approach
}

\author{
Adolfo Sachsida $^{1}$, Mário J. C. Mendonça ${ }^{1}$, Paulo R. A. Loureiro ${ }^{2}$, Antônio Nascimento Junior ${ }^{3}$, Roberto Ellery ${ }^{2}$ \\ $\&$ Tito Belchior Silva Moreira ${ }^{4}$ \\ ${ }^{1}$ Institute of Applied Economic Research, Brazil \\ ${ }^{2}$ University of Brasilia - UnB, Brazil \\ ${ }^{3}$ Business Administration, University of Brasilia (UnB), Brazil \\ ${ }^{4}$ Catholic University of Brasilia, Brazil \\ Correspondence: Paulo R. A. Loureiro, Departamento de Economia (ECO) - ICC / Entrada Norte Campus Darcy \\ Ribeiro-Asa Norte - postal code: 70362-010, University of Brasília-UnB, Brasilia, DF, Brazil. Tel: 55-61-3307- \\ 2498. E-mail: pauloloureiro@unb.br
}

Received: January 9, 2018

doi:10.5539/ijef.v10n3p196
Accepted: February 11, 2018

Online Published: February 20, 2018

URL: https://doi.org/10.5539/ijef.v10n3p196

\begin{abstract}
This paper investigates the existence of wage discrimination to inmates. Based on data collected from the Coordination Center for the Execution of Penalties and Alternative Measures (CEPEMA) for people serving in an open prison in Brasília (DF), a comparative approach was conducted with data collected from PNAD. It was then possible to verify using the decomposition process of Oaxaca-Ransom that there is statistical discrimination regarding to ex-convicts in the job market. Furthermore, it has been noticed that the full labor market participation of prisoners seems to be compromised to the extent that the empiricalresults support the assumption of Nagin and Waldfogel (1993). It indicates that access of the individual who been in prison to the job market is limited to the so-called spot market or temporary labor market. This segment of the labor market should not be confused with the so-called part time.Thus, one of the negative effects that can be understood from this is a reduction in the current value of the individual's discounted income, since long-term jobs are those that offer higher income perspectives.
\end{abstract}

Keywords: crime, discrimination, decomposition of Oaxaca-Ransom, Nagin and Waldfogel hypothesis and Spot market

\section{Introduction}

Over the last few decades, the literature on crime has grown substantially considering issues that go beyond those evaluated by Becker (1968), in which the person's entrance into crime derives from a rational choice that take into account a cost-benefit analysis of staying in legal activity or entering the crime market. Among the new themes, it should be highlighted the effect of detention on crime (detention effect), the use of public policies to avoid crime, and the impact of social interaction and family inheritance on crime (Glaeser et al., 1999), etc.

The discrimination that the ex-prisoner feel in the job marketemerge from his imprisonment, deserving to be highlighted in the research agenda to the extent that if exist an asymmetric barrier to the entry of the ex-prisoner in the job market, the possibility of returning to crime is higher. Imai and Krishna (2001) discuss the existence of a stigma effect that is actually what the literature on discrimination defined as statistical discrimination. Cain (1986) and Phelps (1972) statesstatistical discrimination occurs due toinformation problem. The employers know only partially the characteristics of the worker, so they end up assigning to the employee the average characteristics of the group. Therefore, group characteristics will be associated to the individual even if they do not have them.

There is a vast empirical literature on the monetary cost of discrimination. The main empirical indicate the occurrence of wage diminution after conviction and imprisonment of the convicted person (Waldfogel, 1994; Lott, 1990, 1992). In some countries, for example Sweden, changes in the law are being studied to restrict access to information about the former prisoner. Nagin and Waldfogel (1993) show the existence of a type of perverse discrimination for the one who has served his sentence and faces barriers to his entry into the long-term job 
market, which offers greater wage and stability for the individual. According to Nagin and Waldfogel (1993), because they are stigmatized, ex-offenders only have access to the so-called temporary job market or "spot market".

Berik, Rodgers, and Zveglich (2004) investigate, considering two open economies, Taiwan and Korea; the impact of competition from international trade on gender wage discrimination. The empirical results show thatcompetition viainternational trade in concentrated industries is directly correlatedwith wage discrimination against women.Black and Brainerd (2004) discuss the effect of globalization on gender discriminationin manufacturing industries.The authorsshow that,although trade expandwage inequality based onsmall reductionthe relative wages of less-skilled workers, simultaneously it seems to benefit women since reduce the possibilityof firms to discriminate.

Kawaguchi (2007) evaluates if the male-female wage differential is due to employer discrimination based on the Japanese firm-level panel data from the 1990s. In this context, the author evaluates if non-discriminatory employers will hire more women and, consequently, enjoy a higher profit than discriminatory employers. The empirical results showthat hiring more women imply in higher profit.

Charles and Guryan (2008) discuss the relation between prejudice and wages considering the Becker Discrimination Theory. The estimates indicate that one-quarter of the racial wage gap is due to prejudice; with non-negligible effects on black lifetime earnings.

Baert and Verhofstadt (2015) show evidence of discrimination against former juvenile delinquentsin the Belgian labor marketbased on a field experiment. They indicate that labor market discrimination is a relevant barrier for former juvenile delinquents access the job market.

Hirata and Soares (2016) use the Brazilian trade liberalization from the early 1990s, as a natural experiment, to evaluate the effect of greater competition in the market for final goods on racial discrimination. The authors show empirical evidences of a negative effect of increased competition in the market for final goods on discrimination in the Brazilian jobmarket.

The objective of this study is to analyzeif there is a wage discrimination in the job market for the ex-prisoner based on a sample of individuals who are serving an open sentence, as well as testing the Nagin and Waldfogel hypothesis (1993) regarding the nature of this discrimination. It is important to clarify two points: first, salary discrimination should not be confused with employment discrimination and second, the individuals who are serving an open sentence are convicted prisoners who were granted the right to stay in liberty, but should present themselves once a month to the justice to inform about their activities.Considering that we usethe Oaxaca-Ransom decomposition procedure $(1994,1999)$, it is verified whether there is statistical discrimination in the labor market for ex-offenders comparing this group to a selected sample of the PNAD, so that the results for the two groups can be compared. Moreover, this paperaims to deepen the analysis of the phenomenon of discrimination by verifying whether the Nagin and Waldfogel hypothesis (1993) exists, in which ex-prisoners only find occupation in the labor market in the so-called spot market.

\section{Verifying the Existence of Wage Discrimination for Ex-Offenders}

\subsection{Method of Decomposition of Oaxaca-Ransom}

To investigate the existence of wage discrimination for former prisoners, this study uses the methodology by Oaxaca (1994), which will be described below. In formal terms, the gross wage differential between the non-discriminated and discriminated groups (ex-offenders), $G_{N D}$, is defined by

$$
G_{N D}=W_{N} / W_{D}
$$

where $W_{N}$ represents the salary of the non-discriminated and $W_{D}$ represents the salary of ex-prisoners. In the absence of discrimination, the differential between the groups should reflect only the difference in productivity $Q_{N D}$, expressed as follows:

$$
Q_{N D}=W_{N}^{0} / W_{D}^{0}
$$

where 0 means absence of discrimination. Thus from (1) and (2), the coefficient of discrimination can be defined as being proportional to the ratio between $G_{N D}$ and $Q_{N D}$, that is, $D_{N D}=G_{N D} / Q_{N D}$. Considering the ratio in $\log$, it is understood that

$$
\ln D_{N D}=\ln G_{N D}-\ln Q_{N D}=\ln \frac{W_{N}}{W_{N}^{0}}-\ln \frac{W_{D}^{0}}{W_{D}}=\ln \delta_{N 0}-\ln \delta_{0 D}
$$


where $\delta_{N O}$ is the differential between the current wage and the wage in the absence of discrimination for the non-discriminated, while $\delta_{O D}$ the differential for former prisoners between the wage that would be earned in the absence of discrimination and the current wage. Combining the previous formulas, we have

$$
\ln G_{N D}=\ln \delta_{N 0}+\ln \delta_{0 D}+\ln Q_{N D}
$$

We will now consider that the average wage log for both groups is determined by a wage equation estimated by OLS. Thus, we have $\ln \bar{W}_{N}=\bar{X}_{N}{ }^{\prime} \hat{\beta}_{N}$ and $\ln \bar{W}_{D}=\bar{X}_{D}{ }^{\prime} \hat{\beta}_{D}$, where $\bar{X}$ is the vector of the average values of prisoners and $\hat{\beta}$, the vector of coefficients estimated by OLS. It is concluded that

$$
\ln G_{N D}=\ln \bar{W}_{N} / \bar{W}_{D}=\bar{X}_{N}^{\prime} \hat{\beta}_{N}-\bar{X}_{D}{ }^{\prime} \hat{\beta}_{D}
$$

or that

$$
\ln G_{N D}=\bar{X}_{N}{ }^{\prime}\left(\hat{\beta}_{N}-\beta^{*}\right)+\bar{X}_{D}{ }^{\prime}\left(\hat{\beta}-\hat{\beta}_{D}\right)+\left(\bar{X}_{N}-\bar{X}_{D}\right)^{\prime} \beta^{*}
$$

where $\beta^{*}$ is the coefficient relative to a non-discriminatory structure. From equation (5) it can be concluded that the first term of equation (6') is an estimate for the wage advantage of those previously discriminated, $\ln \delta_{N o}$ in a discriminating context, the second term of (6') being an estimate of the wage disadvantage of former prisoners $\ln \delta_{O D}$ in the same discriminatory context. Finally, the last term of the equation (6') is an estimate of the productivity differential, $\ln Q_{N D}$. As demonstrated, it is necessary to specify some hypothesis about the wage structure where there is no discrimination. $\beta^{*}$ can be expressed as follows

$$
\beta^{*}=\Omega \hat{\beta}_{N}+(I-\Omega) \hat{\beta}_{D}
$$

where $\Omega$ it is a weight matrix.

Considering the above, in order to obtain the decomposition of the discrimination in its components, it is necessary first to obtain the estimates for $\beta_{N}, \beta_{D}$ and $\Omega$. Estimates for $\beta_{N}$ and $\beta_{D}$ in general are obtained by means of the mincerian equation to determine the wage estimated by OLS and defined as follows,

$$
w_{i}=\ln W_{i}=\alpha+\beta S_{i}+\delta X_{i}+u_{i}
$$

where $W$ is a measure of income or salary, $S$ is a measure of schooling taken in general in number of years of schooling or degrees completed, $X$ a set of variables that may also have an effect on income, and $u$ is the random disorder involving all forces not directly explained in the model, but that have influence on the gains of the individual.

The reason the salary taken in the log is because equation (1) results from the solution of an optimal choice problem of the agent regarding the impact of the educational level on its future minus the income. The equation is usually called Mincer equation (Griliches, 1977). The Mincer equation is largely used in studies about salary discrimination (Oaxaca, 1973) and (Oaxaca \& Ransom, 1994). Needless to say, the model only works with people entering the labor market, which is not a problem since we are dealing with wage discrimination and not discrimination in employment. Salary discrimination is defined as the probability of being hired, and it is a difficult measurement, because it is necessary to consider not only the employer selection process, but the employee decision to be partof the labor force. Thus, the employment probability is formed by a bivaried process of sequential decision with partial observation, once it is unknown what could have happened if the individual who didn't look for employment had look for one. (Abowd \& Farmer, 1982; Heywood \& Mohanty, 1995; Moranty, 2002). Among the most common variables to explain the salary, one can highlight experience, gender, ethnicity, parents' education, health, union membership, etc.

In relation to the proper choice for the matrix $\Omega$ in the determination of $\beta^{*}$, there is no agreement in respect to the most efficient matrix. Some authors make use of a type-weight matrix $\Omega_{c}=l_{N} I$, where $l_{N}$ is the fraction of non-discriminated individuals, and $I$ is the identity matrix, so that $\beta^{*}=l_{N} I \beta_{N}+\left(1-l_{N}\right) I \beta_{D}$ (Cotton, 1988). However, other definitions of the weight matrix may also be used as below.

\subsection{Database, Selection and Descriptive Statistics of Variables}

According to Willis and Rosen (1979) the set of explanatory variables is small when compared to other researches. In this set, education, age, experience $(\exp )$ where Experience $=$ age-education- 6 , quadratic experience (exp2), mother's education (estmae), and dummy variables to exemplify the fact that the worker is 
unionized (sind), is part of the formal labor market (formal) and is white (branco). A dummy variable has also been created, meaning the value equal to 1 (one) if the individual belongs to the sample of prisoners and 0 (zero), otherwise.

Our database is made up of 417 inmates complying with an open regime. Those are convicted prisoners in which were granted the right to stay in liberty, but should present themselves once a month to the justice to inform about their activities.Data for prisoners were obtained through direct interviews with inmates. The interviews were authorized by the Federal and the Territories District Court, and by the Court of Criminal Executions. Data was collected when prisoners, in compliance with an open regime, presented themselves at the Coordination Center for the Execution of Penalties and Alternative Measures (CEPEMA). The questions elaborated were based on studies of return to education. It means people answered the same questions commonly used in studies that attempt to measure returns in education.

The sample used for ordinary people was obtained from the 1996 National Household Sample Survey data (PNAD/1996). Basing in other studies on returns to education, it was necessary to select a subgroup of this sample. Some filters were performed: first, our sample is composed exclusively by males between 24 and 56 years old, as their decisions about the level of education are less complicated by fertility considerations (Cameron \& Heckman, 2001). Bratsberg and Terrell (2002), Heckman et al. (2000), Soares and Gonzaga (1997) and Garen (1984), also restrict their samples to men only. The second filter implies that only people who are not studying will be included in this sample. Bratsberg and Terrell (2002), Heckman, Tobias, and Vytlacil (2000) and Garen (1984) also use this procedure. The third filter removes from the sample situations in which observation does have incomplete information on the independent variables, this procedure appears in Heckman et al. (2000). Garen (1984) estimates two regressions: the first using incomplete observations and the second using a sample with observations including all information available.The fourth filter attempts to prevent people from being included in the sample if: (i) have an extremely high salary that can bias the results; and ii) who are not working. In this way, this filter causes the sample to be composed only of individuals who receive an hourly wage between BRL \$ 1.00 and BRL \$ 500.00. Heckman, Tobias, and Vytlacil (2000) restrict their sample to people who are paid between U\$1,00 and $\$ 100,00$ per hour. Moreover, due to the dynamics that govern the public administration and the agricultural sector of the Brazilian economy, people employed in these sectors were also excluded from the sample (Soares \& Gonzaga, 1997). Finally, we should point out that our sample was restricted to the inhabitants of the Federal District. After these filters, the sample of ordinary people was reduced to a set of 1,267 observations.

Table 1 shows preliminary information regarding the descriptive statistics of the variables that appear in this research. As it can be seen in this table, the data is grouped in three distinct ways. Column (1) refers only to non-inmates, while column (2) shows the statistics for the sample of ordinary people drawn from the PNAD. Finally, in column (3) the data is taken in relation to the complete sample.

Table 1. Descriptive statistics of variables

\begin{tabular}{|c|c|c|c|}
\hline Variables & $\begin{array}{c}\text { Prisoners } \\
\text { (1) } \\
\end{array}$ & $\begin{array}{c}\text { PNAD } \\
(2) \\
\end{array}$ & $\begin{array}{c}\text { Irrestrict } \\
\text { (3) } \\
\end{array}$ \\
\hline & Average (Standard Deviation) & Average (Standard Deviation) & Average (Standard Deviation) \\
\hline SALARY & $615,19 \quad(650,05)$ & $1483,03 \quad(1962,61)$ & $1268,13 \quad(1772, .65)$ \\
\hline EDUCATION & $7,25 \quad(2,81)$ & $8,23 \quad(4,65)$ & $7,971 \quad(4, .275)$ \\
\hline AGE & $29,41(9,45)$ & $36,23 \quad(8,62)$ & $34,446 \quad(9,125)$ \\
\hline EXPERIENCE & $16,02 \quad(9,06)$ & $22,00 \quad(9,96)$ & 20,466 \\
\hline UNION & $0,179 \quad(0,384)$ & $0,299(0,458)$ & 0,268 \\
\hline FORMAL & $0,214 \quad(0,410)$ & $0,388 \quad(0,487)$ & 0,343 \\
\hline MOTHER'S EDUCATION & $3,93 \quad(3,504)$ & $(3,106)$ & 3,649 \\
\hline BRANCA & $0,236 \quad(0,425)$ & $0,462 \quad(0,498)$ & 0,404 \\
\hline
\end{tabular}

Some preliminary comments can be made from the reading of Table 1. Initially, it is observed that the PNAD sample selection was elaborated efficiently. Comparing the values of the average and the variance between the two groups, it is observed that there is not a very pronounced difference between these measures for each one of the variables, with the exception of the salary. Thus, preliminary, it seems that there is an indication that a large salary differential cannot be explained only by the difference in endowment, which highlights the existence of discrimination. 


\subsection{Results of the Oaxaca-Ransom Decomposition}

Before presenting the Oaxaca-Ransom decomposition results for the wage differential, it is necessary to estimate the wage or mincer equation for each of the groups, which is shown in Table 1, whose estimates are obtained by OLS. Although it is known as stated by Griliches (1977), OLS estimation for the mincer equation can generate biased estimates due to several types of problems (Grichiles, 1977; Garen, 1984), especially with respect to obtaining the parameter $\beta$ related to the return to education due to the endogeneity of the educational variable, which would require the use of a method to correct variables, such as the use of instrumental variables. However, as the goal at this point is aimed at the decomposition of Oaxaca, this problem will be set aside.

According to the results of Table 1, in most cases the variables are significant, and the signs found are in agreement with those that appear in other studies that estimate the wage equation. The negative sign for exp2 also conforms to what is seen in the literature and points out only that the individual's experience obeys the law of diminishing marginal incomes. The exception here is due only to the signal found for the formal variable that is negative here, unlike other studies, however, this is a particular characteristic of the labor market of the Federal District.

Table 2. Equation for the logarithm of the monthly salary by OLS*

\begin{tabular}{lcc}
\hline Independent Variable & EX-CONVICTS & PNAD \\
\hline S & 0,123 & 0,142 \\
& $(0,000)$ & $(0,000)$ \\
Exp & 0,025 & 0057 \\
& $(0,000)$ & $(0,000)$ \\
Exp2 & $-0,001$ & $-0,001$ \\
& $(0,000)$ & $(0,000)$ \\
Formal & $-0,116$ & $-0,210$ \\
& $(0,056)$ & $(0,001)$ \\
Sind & 0,418 & 0,276 \\
& $(0,000)$ & $(0,000)$ \\
Branco & 0,038 & 0,232 \\
& $(0,020)$ & $(0,000)$ \\
Same & 0,014 & 0,013 \\
& $(0,049)$ & $(0,232)$ \\
Constante & 4.598 & 4.215 \\
& $(0,000)$ & $(0,000)$ \\
\hline Adjusted $\mathbf{R}^{2}$ & 0,400 & 0,523 \\
Notes & 395 & 1402 \\
\hline
\end{tabular}

*: Values in parentheses are p-valores.

Once obtaining the wage equations for the different groups, the following concerns the application of the methodology presented in section 2.1 for wage differential analysis, which is shown in Table 3 . Before analyzing the results, comments on some of the contents that appear in Table 3 are necessary.

By replacing the expression (7) into (6'), it is possible to define $\ln G_{N D}$ as

$$
\ln G_{N D}=E+C+C E
$$

where $E$ represents the portion of the salary difference explained by the appropriations, $C$ the portion of the differential attributed to the discrimination, while $C E$ is linked to the interaction of attributes and coefficients. The question that arises is how to distribute $C E$ between $C$ and $E$. In general, the distribution is done by the weight matrix $\Omega$. (8) have direct relation to the equation (6'). In Table 3, the Oaxaca-Ransom decomposition is calculated for several values $\Omega$, including grouped data (pooled) when $\beta^{*}$ is estimated by merging the data from both groups.

Considering the results shown in Table 3, it can be observed that a large part of the wage differential between the groups is due to the discrimination, and for the different values attributed to the weight matrix $\Omega$, there are not great differences for this measure. Here, with the exception of the calculation of pooled data, the wage differential between ordinary and ex-prisoners attributed to discrimination is in the range of 49.0 to 55.0 percent, which demonstrates the consistency of the Oaxaca-Ransom procedure in the current case. As concluded by other 
authors (Waldfogel, 1994; Lott, 1990, 1992), it can be said that there is in fact discrimination in the labor market for former prisoners with a substantial reduction of their salary.

Table 3. Decomposition of Oaxaca-Ransom (PNAD x Ex-prisoners)

\begin{tabular}{lccccc}
\hline Specifications & $\Omega=\mathbf{0}$ & $\Omega=\mathbf{I}$ & $\Omega=\mathbf{0 . 5} * \mathbf{I}$ & Cottom & Pooled \\
\hline Lw: Predicted Average PNAD = 6,926 & & & & & \\
Lw: Predicted Average PRESOS = 6,130 & & & & & \\
Gross Differential(R) = 0,796 & 0,386 & 0,437 & 0,411 & 0,422 & 0,311 \\
Attributed to discrimination $(\mathrm{U})=\mathrm{C}+(1-\Omega) * \mathrm{CE}$ & 0,409 & 0,359 & 0,384 & 0,374 & 0,485 \\
Attributed to dotations $(\mathrm{V})=\mathrm{E}+\Omega * \mathrm{CE}$ & 48,6 & 54,9 & 51,7 & 53,0 & 39,1 \\
Attributed to discrimination (U/R) & 51,4 & 45,1 & 48,3 & 47,0 & 60,9 \\
Attributed to dotations (V/R) & & & & & \\
\hline
\end{tabular}

\section{Implications of Wage Discrimination for the Life Cycle of Agents}

In the previous section, the existence of wage discrimination for ex-prisoners in the labor market was verified. It can be concluded from the application of the methodology of Oaxaca-Ransom that the data corroborates the existence of statistical discrimination for ex-prisoners. The purpose of this section is to discuss the nature of this discrimination. As stated in the introduction, according to Nagin and Waldfogel (1993) one of the consequences of imprisonment is reflected in the instability of employment, meaning that it is more difficult for individuals who have been imprisoned to have a stable job. Stable job is defined as a situation where the individual can develop his career or stays for long term in a position. If the individual is not included in this segment of the labor market, it is said that they are in the short-term labor market or spot market.

In terms of the wage dynamics and trajectory of agents' income over time, belonging to one or another market has important implications. Of the most visible characteristics between both markets is the fact that the wage level for early stages in the stable segment tends to be lower than in the spot market. However, this situation changes in medium and long-term, making wages in the stable market well above that of the spot market. The explanation for this series of events in these two markets is basically due to the combination of three factors: training, experience and incentive to remain in the position.

In relation to training, little or no specific training is given to the individual who will enter the spot market. In the other hand, in long-term occupations firms usually invest in training, and no specific knowledge is generally required, except for academic training or that the agent at least has some basic training. Once the firm has invested in the formation of human capital, it is natural for it to make an effort to make it less attractive for its employee to change jobs. This can be done in several ways and the most common one would be to introducing an incentive program for the employee with the gradual increase of salary, etc. Differently, in the type of short-term employment, due to the nature of the activities of this market almost nothing is observed in terms of training, and incentive programs are more related to the achievement of goals than the specific permanence of the worker. Both are due to the ease of replacing labor in the spot market.

Regarding the requirement or experience in both markets, this is an important point and is supported by the sample data. It is common for the long-term labor market that the individual has limited or no experience. Some companies prefer people who have no experience because they are not yet stigmatized. It is understood here that we are dealing with young people entering the labor market. Experience has little relevance when it comes to the insertion of young individuals into the long-term labor market. In the other hand, for older individuals, experience is a mandatory requirement for entering or remaining in this market.

In regards to the spot market, it is the opposite: for young individuals, experience is important and then it is replaced by maturity or responsibility to the execution of the task and not knowledge obtained within the years. For adults, experience has little relevance. As shown by Nagin and Waldfogel (1993), there is evidence that the income of people who have been imprisoned is negatively impacted throughout life because they are stigmatized, thus being left out of the long-term labor market. In order to observe if there is evidence if our data confirm this hypothesis, we will adopt the following procedure: for both samples, ex-offenders and PNAD, we will work with two sub samples: individuals below the age of 25 and above it. The objective is to observe how the variable experience reacts. If the hypothesis that ex-offenders are confined to the spot market, it is expected that for the sample with individuals over 25 , the coefficient of this variable will have little or no significance, the opposite occurring for individuals below the age of 25 . 
Considering the information presented in Table 4, it is observed that the results seem to corroborate the hypothesis of discrimination for ex-prisoners regarding the category of employment. The coefficient of the EXP variable accurately reflects the desired pattern accordingly to corroborate the fact that ex-inmates are confined to a specific segment of the labor market. For the sample of ex-prisoners with people above 25 years of age, the coefficient of EXP shows no significance, which contrasts radically with the results of the sample selected from the PNAD for the same salary range. It is also observed that for the sub-sample of ex-offenders under 25 years of age, EXP is significant at the 5\% level, differently from that of the PNAD sample for a similar age range.

Table 4. Equation for the logarithm of the monthly salary (Before/after 25 years)

\begin{tabular}{|c|c|c|c|c|}
\hline \multirow[t]{2}{*}{ Independent Variables } & \multicolumn{2}{|c|}{ Ex-Prisoners } & \multicolumn{2}{|c|}{ PNAD Sample } \\
\hline & Age $<=25$ & Age $>25$ & Age $<=25$ & Age $>25$ \\
\hline \multirow[t]{2}{*}{$S$} & 0,111 & 0,121 & 0,117 & 0,143 \\
\hline & $(0,000)$ & $(0,000)$ & $(0,000)$ & $(0,000)$ \\
\hline \multirow[t]{2}{*}{ Exp } & 0,127 & 0,007 & 0,084 & 0,053 \\
\hline & $(0,050)$ & $(0,691)$ & $(0,120)$ & $(0,000)$ \\
\hline \multirow[t]{2}{*}{ Exp2 } & $-0,004$ & $-0,001$ & $-0,003$ & $-0,001$ \\
\hline & $(0,004)$ & $(0,202)$ & $(0,200)$ & $(0,001)$ \\
\hline \multirow[t]{2}{*}{ Sind } & 0,288 & 0,431 & 0,154 & 0,225 \\
\hline & $(0,024)$ & $(0,000)$ & $(0,078)$ & $(0,000)$ \\
\hline \multirow[t]{2}{*}{ Formal } & $-0,091$ & $-0,128$ & $-0,324$ & $-0,188$ \\
\hline & $(0,336)$ & $(0,232)$ & $(0,000)$ & $(0,000)$ \\
\hline \multirow[t]{2}{*}{ Branco } & 0,010 & 0,057 & 0,257 & 0,240 \\
\hline & $(0,003)$ & $(0,040)$ & $(0,000)$ & $(0,000)$ \\
\hline \multirow[t]{2}{*}{ Smae } & 0,015 & 0,015 & 0,013 & 0,010 \\
\hline & $(0,101)$ & $(0,210)$ & $(0,257)$ & $(0,151)$ \\
\hline \multirow[t]{2}{*}{ Constante } & 4,168 & 5,041 & 6,026 & 4,789 \\
\hline & $(0,000)$ & $(0,000)$ & $(0,000)$ & $(0,000)$ \\
\hline Adjusted R2 & 0,201 & 0,201 & 0,430 & 0,524 \\
\hline Notesl & 181 & 214 & 267 & 1135 \\
\hline
\end{tabular}

\section{Final Remarks}

This study aimed to verify the existence of wage discrimination for ex-prisoners. Based on a comparative study of the data collected from the Coordination Center for the Execution of Penalties and Alternative Measures (CEPEMA) for persons serving an open sentence in the city of Brasília (DF) and a sample selected from the PNAD, it was possible to verify the application of the decomposition procedure of Oaxaca-Ransom that there is statistical discrimination against ex-prisoners in the labor market.

In addition, it was noted that the full labor market insertion for the individual that has been imprisoned seems to be even more compromised as the results corroborate the Nagin and Waldfogel hypothesis (1993) that the access of these individuals is restricted to the so-called spot market or temporary labor market in which training, experience and incentive show little relevance. This segment of the labor market should not be confused with the so called "part time".

Thus, one of the perverse effects that can be deduced from this is a decrease in the present value of the discounted income of the individual, since long-term employment is the one that offers better expectations of wages.

Among the suggestions for public policies that can be obtained from this research, we highlight the one indicating that once the prisoners are confined, it would be appropriate to fit them into some program that would allow them to maintain a link with the labor market in order to insert it into a trajectory of long-term employment, thus helping to reduce the stigma of ex-convict. Otherwise, if nothing is done, prisoners will know that they will only have access to unattractive jobs that do not provide stability throughout the life cycle, which is another factor that can lead to a return to crime.

\section{References}

Abowd, J. M., \& Farmer, H. S. (1982). Job Queues and Union Status of Worker. Industrial and Labor Relations Reviews, 35, 354-67. https://doi.org/10.1177/001979398203500305. 
Anonymous. (1958). Investment in Human Capital and Personal Income Distribution. Journal of Political Economy, 66(4), 281-302. Retrieved from http://www.nber.org/books/minc74-1

Baert, S., \& Verhofstadt, E. (2015). Labour market discrimination against former juvenile delinquents: Evidence from a field experiment. Applied Economics, 47(11). https://doi.org/10.1080/00036846.2014.990620

Becker, G. (1968). Crime and Punishment: An Economic Approach. Journal of Political Economy, 101, 169-217. https://doi.org/10.1086/259394

Berik, G., Van Der Meulen Rodgers, Y., \& Zveglich, J. (2004). International Trade and Gender WageDiscrimination: Evidence from East Asia. Review of Development Economics, 8(2), 237-54. https://doi.org/10.1111/j.1467-9361.2004.00230.x

Black, S. E., \& Brainerd, E. (2004). Importing equality? The impact of globalization on gender discrimination. Industrial and Labor Relations Review, 57(4), 540-559. https://doi.org/10.1177/001979390405700404

Cain, G. (1986). The Economic Analysis of Labor Market Discrimination: A Survey. In Handbook of Labor of Econometrics (vol. 1). Amsterdam: North-Holland. Retrieved from https://trove.nla.gov.au/version/22816913

Card, D. (2001). Estimating the Return to Schooling: Progress on Some Persistent Econometric Problems. Econometrica, 69(5), 1127-1160. Retrieved from http://www.jstor.org/stable/2692217

Charles, K., Guryan, J. (2008). Prejudice and wages: An empirical assessment of Becker's "The economics of discrimination." Journal of Political Economy, 116(5), 773-809. https://doi.org/10.1086/593073

Cotton, J. (1988). On the Composition of Wage Differentials. The Review of Economics and Statistics, 70(2), 236-243. Retrieved from http://www.jstor.org/stable/1928307

Davidson, R., \& MacKinnon, J. G. (1993). Estimation and Inference in Econometrics. New York: Oxford University Press.

Glaeser, E. L., Sacerdote, B., \& Scheinkman, J. A. (1996). Crime and Social Interactions. Quarterly Journal of Economics, 111, 507-548. https://doi.org/10.2307/2946686

Greene, W. (1993). Econometric Analysis. Prentice Hall.

Griliches, Z. (1977). Estimating the Returns to Schooling: Some Econometrics Problems. Econometrica, 45(1), 1-22. Retrieved from http://www.jstor.org/stable/1913285

Heywood, J. S., \& Mohnty, M. S. (1995). Estimation of the US Federal Job Queue in the Presence of an Endogenous Union Queue. Economica, 62, 479-93. https://doi.org/10.2307/2554672

Hirata, G., \& Soares, R. R. (2016). Competition and the Racial Wage Gap: TestingBecker's Model of Employer Discrimination. IZA Discussion Paper No. 9764. Retrieved from https://ssrn.com/abstract $=2742552$

Imai, S., \& Krishna, K. (2001). Employment, dynamic deterrence and crime. NBER Working paper n. w8281. Retrieved from http://www.nber.org/papers/w8281

Kawaguchi, D. (2007). A market test for sex discrimination: Evidence from Japanese firm level data. International Journal of Industrial Organization, 25(3), 441-460. https://doi.org/10.1016/j.ijindorg.2006.05.006

Levitt, S. D. (1996). The Effect of Prison Population Size on Crime Rates: Evidence from Prison Overcrowding Litigation. Quarterly Journal of Economics, 111, 320-351. https://doi.org/10.3386/w5119

Meng, C., \& Schmidt, P. (1985). On the Cost of Partial Observability in the Bivariate Profit Model. International Economic Review, 26, 71-86. https://doi.org/10.2307/2526528

Mincer, J. (1974). Schooling, Experience and Earnings. National Bureau of Economic Research.

Mohanty, M. S. (2002). A Bivariate Probity Approach to the Determination of Employment: A study of teen employment differentials in Los Angeles County. Applied Economics, 34, 143-156. https://doi.org/10.1080/00036840010028585

Nagin, D., \& Waldfogel, J. (1993). The Effect of Conviction on Income Through the Life Cycle. NBER Working Paper Series No. 4551. https://doi.org/10.3386/w4551

Oaxaca, R. (1973). Male-Female Wage Differentials in Urban Labor Market. International Economic Review, 14, 693-704. https://doi.org/10.2307/2525981

Phelps, E. S. (1972). The Statistical Theory of Racism and Sexism. American Economic Review, 62, 659-661. 
Retrieved from http://www.jstor.org/stable/1806107

Ronald, L. O., \& Michael, R. R. (1994). On Discrimination and Decomposition of Wage Differentials. Journal of Econometrics, 61, 5-21. https://doi.org/10.1016/0304-4076(94)90074-4

Ronald, L. O., \& Michael, R. R. (1999). Identification in the Detailed Wage Decomposition. The Review of Economics and Statistics, 81(1), 154-157. https://doi.org/10.1162/003465399767923908

STATA. (n. d.). Stata User's Guide, Release 8. College Station, Texas: Stata Press. Retrieved from https://www.stata.com/manuals13/u.pdf

Willis, R. J., \& Rosen, S. (1979). Education and Self Selection. Journal of Political Economy, 87(5), S7-S36. Retrieved from http://www.jstor.org/stable/1829907

\section{Copyrights}

Copyright for this article is retained by the author(s), with first publication rights granted to the journal.

This is an open-access article distributed under the terms and conditions of the Creative Commons Attribution license (http://creativecommons.org/licenses/by/4.0/). 